\title{
A Collaborative Learning Proposal for Predict-Observe-Explain Model supported by Mobile Environment
}

\author{
Fernando Gagno Júnior', Walber Antonio Ramos Beltrame ${ }^{2}$ \\ ${ }^{1}$ Guarapari City Department of Education (SEMED) \\ PO Box 29.210-520 - Guarapari - ES - Brazil \\ ${ }^{2}$ Department of Education, Federal Institute of Espírito Santo (IFES) \\ PO Box 29.216-795 - Guarapari - ES - Brazil \\ \{gagnojr, walber.beltrame\} @gmail.com
}

\begin{abstract}
Virtual learning environments were designed to stimulate social competences, such as altruism, responsibility, communication, planning and coordination. It is observed that creation of technology for active methods, as for the Predict-Observe-Explain (POE) model. However, advances in the design of these environments are necessary to support aspects of collaboration and mobility. The goal of this article is to present a proposal for a mobile platform that organizes a workflow of revised POE models, based on debates. The methodology and expected results are presented.
\end{abstract}

\section{General Information}

Active methodologies have emerged in an attempt to make learning more practical and critical, focusing on activities involving experiments, research, analysis, reasoning and other skills, also using non-formal spaces and applications of information technologies, such as virtual environments, augmented reality and immersive systems. In a socio-constructivist perspective, it is necessary to combine these measures with collaborative mediation actions, valuing collective intelligence, exchange of experiences, substantiality and proximal development.

According to these approaches, collaborative environments were designed to stimulate social skills, for example, responsibility, communication, planning and coordination (Brandon and Hollingshead, 1999) (Kirschner et al. 2004) (Wang, 2009). As an evolution of these possibilities, there are proposals for educational mobile applications (Park, 2011), motivated by use of mobile device technologies, such as immediate communication, multimedia resources and geolocation services.

Some active methodologies, such as Predict-Observe-Explain (POE) model (White and Gunstone, 1992) (Tao and Gunstone, 1999), also serve as guidelines for development or use of technologies (Küchemann et al., 2020) (Fitriani et al., 2020a) (Fitriani et al., 2020b). However, advances are needed in design or adaptation of these environments, in order to support aspects of collaboration and mobility. 


\section{Collaborative learning proposal}

In disciplines such as science, the POE method is applied with intention that, after predicting a phenomenon or experiment, differences between predictions and observations arise, so that students become aware between allegation and observation, resulting in cognitive conflict (Vaara and Sasaki, 2019). From this, the central idea is to show spontaneous conceptions, to take students to overcome their convictions and create a change in conceptual profile.

Although use of the POE method is widely reported in literature, the number of studies that use it associated with computer systems is quite limited (Küçüközer, 2013). Thus, one of the objectives of this work is to present a proposal for a platform that organizes the workflow of these activities, so that it is facilitated and monitored in a mobile application. Another central point to be addressed is the expansion of traditional POE to new collaborative events.

In this adaptation, students initially continue with the role of raising assumptions about a virtual experiment (texts, photos, videos, files, hyperlinks and simulations) and writing them down in the environment. Larson et al. (2006) reports an engagement strategy to insert an icebreaker activity. Students are not expected to have a clear hypothesis, in strictest sense, but an informal description or understanding. Ruiz-Primo et al. (2010) states that it is possible to obtain information about the students' conceptions from what they write or communicate.

After this stage, with the aid of application, the teacher identifies common and contradictory statements, now as formal hypotheses. At this point, the participant must express his opinion on theses, indicating whether he agrees or disagrees, justifying himself based on arguments and evidence (short responses in hypertexts). This collaborative learning model is based on Nevado et al. (2012).

In the third moment, the apprentices assume another role, as arbiters of choices of other colleagues, confronting discussions, as peer review. The next step is the opportunity to make replicas, in which students accept or not the assessments. When reviewing criticisms, they can reinforce or reconsider their own opinions, seeing new concepts.

Finally, for each hypothesis raised, the student established dialogues with colleagues who reviewed the arguments and those from whom they reviewed. Soon, the apprentice started to have several positions to consider. Thus, supported by additional content suggested by the teacher, he will be able to redo the initial positioning from these interactions. This dynamic can be modified to support group, rather than individual, stages.

For this proposal to be established, it is necessary to design the computational support that meets the learning requirements of each phase, in a configurable and flexible way, in which teachers assume moderation functions to set deadlines, mediate conflicts and interact in case of doubts. During this process, the teacher guides the methodological aspects so that, in the end, it evaluates and validates the reconstructions. 


\section{Expected Results}

The project is in its initial research phase, with the methodological proposal of the stages of systematic review of concepts, rationale and proposition of mobile application model, construction of environment from mold and use of this system through applied case studies.

With regard to the experiments, a participatory observation approach is proposed, with qualitative descriptive analysis in public elementary schools, during disciplines related to science and mathematics. The objective is to report behaviors, emotions and didactic results according to technological proposal, with an interpretative view of reports.

In parallel with these procedures, we intend to carry out a quantitative methodological approach, with the application of descriptive research, based on the results observed during these uses, through questionnaires about the students' perception of the environment, such as ease, navigability, usability and ability to maintain attention, to be pleasant and to promote interaction between students and teachers, in order to promote the improvement of learning mediation.

Among the expected contributions with this proposal is the discussion of how the insertion of a collaboration model supported in a mobile environment enhances the POE method, providing a review of this pedagogical practice and directing it to a constructivist viewpoint.

Therefore, it is also expected to investigate the use of cell phones in face-to-face and experimental practices as a didactic tool, in order to overcome stigmas and fears, from the case demonstrations applied in basic education, explaining the challenges, errors and successes of the revised POE dynamic.

\section{References}

Brandon, D. P., \& Hollingshead, A. B. (1999). Collaborative learning and computer-supported groups. Communication education, 48(2), 109-126.

Fitriani, A., Zubaidah, S., Susilo, H., \& Al Muhdhar, M. H. I. (2020a). PBLPOE: A learning model to enhance students' critical thinking skills and scientific attitudes. International Journal of Instruction, 13(2), 89-106.

Fitriani, A., Zubaidah, S., Susilo, H., \& Al Muhdhar, M. H. I. (2020b). The effects of integrated problem-based learning, predict, observe, explain on problem-solving skills and self-efficacy. Eurasian Journal of Educational Research, 2020(85), 45-64.

Kirschner, P., Strijbos, J. W., Kreijns, K., \& Beers, P. J. (2004). Designing electronic collaborative learning environments. Educational technology research and development, 52(3), 47.

Küchemann, S., Klein, P., Fouckhardt, H., Gröber, S., \& Kuhn, J. (2020). Students' understanding of non-inertial frames of reference. Physical Review Physics Education Research, 16(1), 10112.

Küçüközer, H. (2013). Designing a powerful learning environment to promote durable conceptual change. Computers and Education, 68, 482-494. 
Larson, M. B., Rubbo, L. J., Zaleski, K. D., \& Larson, S. L. (2006). Science Icebreaker Activities: An Example from Gravitational Wave Astronomy. The Physics Teacher, 44(7), 416-419.

Nevado, R. A., Menezes, C. S., \& Júnior, R. R. V. (2012). Debate de teses - uma arquitetura pedagógica. In Brazilian Symposium on Computers in Education (SBIE).

Park, Y. (2011). A pedagogical framework for mobile learning: Categorizing educational applications of mobile technologies into four types. International Review of Research in Open and Distributed Learning, 12(2), 78-102.

Ruiz-Primo, M. A., Li, M., Tsai, S. P., \& Schneider, J. (2010). Testing one premise of scientific inquiry in science classrooms: Examining students' scientific explanations and student learning. Journal of Research in Science Teaching, 47(5), 583-608.

Tao, P. K, \& Gunstone, R. F. (1999). Conceptual Change in Science through Collaborative Learning at the computer. International Journal of Science Education, 21(1), 39-57.

Vaara, R. L., \& Sasaki, D. G. G. (2019). Teaching kinematic graphs in an undergraduate course using an active methodology mediated by video analysis. Lumat, 7(1), 1-26.

Wang, Q. (2009). Design and evaluation of a collaborative learning environment. Computers \& Education, 53(4), 1138-1146.

White, R., \& Gunstone, R. (1992). Probing understanding (The Falmer Press (ed.)). Routledge. 